\title{
ESPAÇOS SUBALTERNOS E TRABALHO ESCRAVO \\ CONTEMPORÂNEO: migração e vulnerabilidade socioeconômica no Maranhão moderno
}

\section{SPACES SUBALTERN AND SLAVE LABOR CONTEMPORARY: migration and socio-economic vulnerability in modern Maranhão}

\author{
Sávio José Dias Rodrigues \\ Doutor em Geografia (UFC) \\ Professor Adjunto I da Universidade Federal do Maranhão \\ saviodiasbr@hotmail.com
}

\section{Resumo}

Temos a intenção de analisar a vulnerabilidade para o trabalho escravo contemporâneo da mão de obra migrante maranhense tomando a ideia de espaços subalternos e expansão territorial do capitalismo. A partir do materialismo histórico, fizemos uma revisão bibliográfica associada com a busca de dados em fontes como a Comissão Pastoral da Terra (CPT) e o Ministério do Trabalho e Emprego (MTE), buscando a dinâmica do trabalho escravo contemporâneo de 2003 a 2013. Os espaços subalternos se reproduzem no capitalismo a partir de várias escalas. Na verdade, a ideia de espaços subalternos carrega a possibilidade de manutenção de lógicas contraditórias e não antagônicas, em que o trabalho escravo como forma não capitalista de apropriação do trabalho, serve à acumulação capitalista, o que pode ser associada à teoria da transferência espacial de valor. Assim, o Maranhão aparece enquanto espaço subalterno do capitalismo brasileiro, fazendo com que na sua modernidade, contraditoriamente, se reproduza o trabalho escravo contemporâneo, que, não antagônico ao modo de produção, faz parte dele na sua dinâmica de reprodução.

Palavras chave: Trabalho escravo. Espaços subalternos. Capitalismo. Vulnerabilidade. Maranhão.

\begin{abstract}
We intend to analyze the vulnerability to the contemporary slave labor of the hand of migrant work maranhense taking the idea of subaltern spaces and territorial expansion of capitalism. From the historical materialism, we made a literature review associated with the search data from sources such as the Pastoral Land Commission (CPT) and the Ministry of Labor and Employment (MTE), seeking the dynamics of the contemporary slave labor 2003-2013. Subaltern spaces reproduce in capitalism from various scales. Indeed, the idea of subordinate spaces carries the possibility of conflicting logical maintenance and not antagonistic to the slave work as noncapitalist form of work ownership, serves capital accumulation, which may be associated with the theory of spatial transfer value. Thus, Maranhão appears as subaltern space of Brazilian capitalism, causing in its modernity, contradictorily, to reproduce the contemporary slave labor, not antagonistic to the mode of production, it is part of the dynamics of reproduction.
\end{abstract}

Keywords: Slavery. Subaltern spaces. Capitalism. Vulnerability. 


\section{Introdução}

O objetivo deste trabalho é analisar a vulnerabilidade para o trabalho escravo contemporâneo da mão de obra migrante maranhense a partir da ideia de espaços subalternos e da expansão territorial do capitalismo. Insere-se na busca por entender os rumos do capitalismo atual e, nesse contexto, entender a reprodução do trabalho escravo contemporâneo, sobretudo, no que se convencionou chamar de modernidade. Dessa forma, a migração de trabalhadores rurais pode ser entendida como parte da mobilização de força de trabalho para o capital e, assim, da reprodução do que estamos chamando de espaços subalternos. Assim, compreender a migração de trabalhadores rurais do Maranhão, entendendo este último como parte da lógica de subalternidade e dentro da estrutura de mobilização de mão de obra se torna essencial.

O Estado do Maranhão, atualmente, se destaca em relação ao uso de mão de obra escrava, sobretudo, como grande exportador de mão de obra que é aliciada para trabalho escravo contemporâneo. A conjuntura de acesso a trabalho e renda, bem como de acesso aos meios de produção nos seus lugares de origem e as condições de sobrevivência e de reproduções debilitadas têm relação com a precariedade dos postos de trabalho que esses migrantes aceitam. Num estudo acerca do trabalho escravo no município de Codó-MA, Flávia de Almeida Moura (2009) se refere às condições dos trabalhadores que foram resgatados de situações de escravidão contemporânea. Segundo ela, a precariedade da sobrevivência desses trabalhadores pode lhes conferir o termo "escravos da precisão", que dá nome a seu livro. Como ela afirma:

[...] essa 'outra forma' de escravidão contemporânea encontrada em Codó apresenta características peculiares. Uma delas é o fato de a atividade denominada de roço da juquira fazer parte das estratégias de sobrevivência desses trabalhadores rurais, uma vez que não há outra oportunidade de trabalho nos locais de residência (MOURA, 2009, p. 29).

Ora, não se trata da opção tomada por esses trabalhadores na escolha desse tipo de ocupação, pura e simplesmente. Aqui, não podemos imaginar a racionalidade da tomada de decisão dos sujeitos como uma linearidade e, sim, considerar a condição material existente em conjunto com outros fatores numa relação complexa. As limitações de acesso dadas pelas condições locais de distribuição de renda e de acesso aos meios de produção e de reprodução se tornam imperativos para as condições de trabalho em que são submetidos e, dessa maneira, analisar essas condições é importante, mas, é preciso 
também ir além e buscar o conjunto de desejos individuais, sonhos diversos, construções culturais, situações familiares. Todos esses elementos nos fazem crer que a dinâmica de migração detém uma complexidade ímpar, além de que o trabalho escravo contemporâneo se nutre da precariedade e da falta de acesso dos trabalhadores a condições de vida dignas.

Assim, este trabalho é dividido em 2 partes principais. A primeira parte trata do que seriam as permanências a partir do debate em torno da modernidade. $\mathrm{O}$ trabalho escravo não como uma forma de exploração do trabalho pré-moderna, mas como parte da própria modernidade. Assim, a subjugação do sujeito como mercadoria, objetificado no trabalho escravo é o ápice das condições impostas pelo modo de produção à força de trabalho. A segunda parte busca entender o Maranhão enquanto espaço subalterno a partir da transferência de valor que se dá no contexto do desenvolvimento desigual do capitalismo. Dessa maneira, o legado do desenvolvimento é interligado ao próprio modo de produção capitalista e ao Maranhão deixa como herança o ônus, a pobreza e a precarização da vida, evidenciada pelo trabalho escravo contemporâneo.

\section{Permanências do trabalho escravo contemporâneo: a modernidade brasileira e os relatos de como o ser humano pode ser objeto}

Quando Neide Esterci (2008) começa sua narrativa descrevendo um trabalhador que desce o rio em cima de uma canoa sob a mira das armas de dois homens, fazendo o leitor se sentir fora do seu tempo, é a descrição de cenas corriqueiras, sobretudo no rural brasileiro. Ele, trabalhador fugitivo, que ia ser entregue na fazenda de onde tinha tido a coragem de escapar, se torna o sujeito do aprisionamento da mão de obra, mas que na atualidade ganha a definição do trabalho escravo contemporâneo.

As denúncias de trabalho escravo seguem o que foi descrito por Neide Esterci (2008), na mesma lógica de cerceamento da liberdade para garantir a força de trabalho quase gratuita, ou ainda, a condição de objeto particular que a mão de obra alcança. Dessa maneira, cada vez mais se percebe a participação do trabalho escravo contemporâneo dentro da estrutura de reprodução do modo de produção capitalista no Brasil e em sua modernização.

Os trabalhadores recrutados e aliciados para o trabalho escravo são mantidos como ferramentas, objetos, sem nenhuma condição de vida e sem dignidade. E os exemplos soam aos montes, divulgados pela mídia, em blogs, portais, jornais. Analisados 
em dissertações, teses, etc. Casos que demonstram como a mão de obra é um item a ser negociado e o sujeito passa a ser apenas um objeto. Como o caso da denúncia feita pelo Ministério Público Federal (MPF) em agosto de 2014 de um produtor de café em Minas Gerais e que mantinha 20 trabalhadores alojados em casas rústicas e sem nenhuma condição de higiene, sem janelas pra ventilação ${ }^{1}$, verdadeiros depósitos de gente.

Alguns dos argumentos levantados pelas defesas de muitos dos réus de manterem trabalhadores em situação de trabalho escravo contemporâneo é de que as ações são erros jurídicos, já que se tratam, na verdade, de ações trabalhistas e não de ações penais. Exemplo é o que ocorreu no caso em que o Ministério Público Federal (MPF) moveu ação contra a Associação Desportiva Rural por manter, no período de funcionamento do empreendimento, pessoas em condições análogas ao trabalho escravo. Na denúncia, constava que os trabalhadores não possuíam Carteira de Trabalho e Previdência Social (CTPS) assinada ou qualquer outro documento de vínculo empregatício, bem como, não havia descanso semanal, ficavam disponíveis ao trabalho a qualquer hora, eram submetidos à sobrecarga de trabalho e excesso de jornada, não possuíam equipamentos de proteção, o alojamento era insalubre, minúsculo e sem ventilação, sem instalações sanitárias adequadas, com alimentação exposta, além de outras irregularidades ${ }^{1}$. Apesar da situação degradante e do trabalho forçado, a interpelação da defesa apresentou como argumentação de que a situação era de violações da legislação trabalhistas. Isso faz crer que os escravagistas naturalizam a agressão à dignidade humana apenas como descumprimento de legislações que regulam relações de trabalho.

No Maranhão, essas situações tornaram-se corriqueiras e tratadas com naturalidade pelos empregadores. Como exemplo, a denúncia de 2009 contra a fazenda Abelha, localizada no município de Codó-MA, que abrigava 36 trabalhadores mantidos como escravos. Segundo relatos dos trabalhadores, essa fazenda era de propriedade do grupo F.C. Oliveira, um dos maiores grupos empresariais da região e que ironicamente financia e participa de campanhas de erradicação do trabalho infantil promovidas por Organizações Não Governamentais (ONGs) no município. Outra denúncia diz respeito a 29 trabalhadores utilizados por carvoaria e que estavam em situação degradante no município de $\mathrm{Bacabal}^{2}$. Essas duas denúncias apresentam o fato de que ou empresas ou atividades associadas ao desenvolvimento do estado tem utilizado de trabalho escravo no seu funcionamento. 
Em 2013, o MPF denunciou a fazenda Santo Antônio, situada no município de Santa Luzia (MA), por manter 24 trabalhadores em situação sub-humana, sendo 2 adolescentes e 2 mulheres que eram mantidos em condições ilegais. A violação passava pela ausência de CTPS e salários e jornada de trabalho em desacordo com a legislação ${ }^{3}$. Porém, o caso que se tornou emblemático de permissividade e naturalização do uso de mão de obra escrava no Brasil, foi o caso que trouxe à tona o nome do juiz estadual Marcelo Baldochi, que no período da denúncia, em 2014, era titular da Comarca de Senador La Rocque no Maranhão. Ele foi denunciado pelo Ministério Público Estadual por uso de mão de obra escrava em uma de suas propriedades, a fazenda Pôr-do-Sol, no município de Bom Jardim, região oeste do estado. A equipe de fiscalização encontrou 25 pessoas, incluindo um adolescente, em condições de trabalho escravo contemporâneo: sem carteira assinada, vítimas de servidão por dívida e de retenção de salário. Os físcais ainda constataram que o alojamento da fazenda era precário e a alimentação inadequada, sem água potável e nem equipamento de segurança ${ }^{4}$. Apesar da denúncia, esse caso foi encerrado com uma derrota, tanto do ponto de vista material como simbólica para os trabalhadores e para o Ministério Público, já que evidenciou uma regressão na leitura da lei. Na defesa do juiz, o relator do processo no Tribunal de Justiça alegou que não havia prova material do crime, e que, ainda, não bastavam condições degradantes de trabalho, havia a necessidade de uma completa sujeição da pessoa e que tenha relação de trabalho com exercício de poder do indivíduo ativo do crime ${ }^{5}$.

Contraditoriamente à leitura do relator, a definição de trabalho é explicita no Código Penal, trazendo assim no seu artigo 149:

Reduzir alguém a condição análoga à de escravo, quer submetendo-o a trabalhos forçados ou a jornada exaustiva, quer sujeitando-o a condições degradantes de trabalho, quer restringindo, por qualquer meio, sua locomoção em razão de dívida contraída com o empregador ou preposto (BRASIL, 1940).

Fica evidente que mesmo com as investigações e os fatos expostos, há uma "proteção" em relação a alguns setores e categorias, tais como do judiciário, empresários e políticos. Todos esses exercem sua influência de várias maneiras ou para barrar as fiscalizações ou para arquivar os processos que lhes envolvem.

A participação de políticos direta ou indiretamente nos casos de trabalho escravo é corriqueira, por exemplo, o caso da fazenda Taiaçu II, no município de Vila Rica (MT) e que pertencia ao irmão da Ministra da Agricultura Kátia Abreu, Luiz Alfredo Feresin de 
Abreu. Com jornadas de 11 horas diárias, 5 pessoas (sendo 2 maranhenses), os trabalhadores moravam em um alojamento sem energia elétrica ou água, com vaso sanitário inutilizado. Os equipamentos que eram fornecidos pela fazenda eram cobrados dos trabalhadores com descontos nos pagamentos, indo de encontro à lei que obriga $\mathrm{o}$ empregador a lhes fornecer esses itens. Segundo a lei 6.514/1977 no seu artigo 166:

\footnotetext{
A empresa é obrigada a fornecer aos empregados, gratuitamente, equipamento de proteção individual adequado ao risco e em perfeito estado de conservação e funcionamento, sempre que as medidas de ordem geral não ofereçam completa proteção contra os riscos de acidentes e danos à saúde dos empregados (BRASIL, Lei 6.514/1977).
}

Apesar dessa medida legal, a prática de se cobrar por equipamentos é tão naturalizada quanto o pagamento de salários baixos ou a não assinatura da carteira. Essa cobrança pode ser comprovada a partir dos cadernos de anotação de dívidas dos trabalhadores, artefato que tem se tornado raro nas fiscalizações em decorrência da modernização da prática. Sendo assim, os relatos dos trabalhadores se tornam importantes nesse aspecto, porém, geralmente, a defesa dos proprietários dos imóveis alega má fé dos fiscais, dizendo que eles suprimiram trechos dos relatos dos trabalhadores.

Ainda em relação ao caso de trabalho escravo contemporâneo na fazenda de Luiz Alfredo Feresin de Abreu, segundo reportagem da Folha de São Paulo: "Em um trecho da defesa, Abreu faz referência à chacina de Unaí (MG), em 2004, quando três fiscais do trabalho foram mortos em uma emboscada". Ao que parece uma tentativa de intimidação, ele assim expõe: “A sorte de Vossa Senhoria e dos fiscais é que eu não tenho personalidade marcada pela psicopatia e acredito na justiça dos homens, senão certamente vocês teriam o mesmo destino daqueles fiscais de Unaí"6. A certeza da impunidade e o sentimento enraizado nas elites brasileiras de que o poder econômico e político se sobrepõem a qualquer legislação é expresso nessas palavras, como se somente a sorte estivesse protegendo os fiscais e nada mais que isso.

O trabalho escravo está imbricado na forma de expansão do modo de produção capitalista no Brasil, indicando que a modernização na agropecuária e na economia urbana não suprime o uso de formas de exploração do trabalho não capitalistas, mas sim, se apropria delas. A assertiva dada por José de Souza Martins (1991) de que existia um conflito entre o Brasil arcaico e forças que o tentavam mordernizar parece ser negada. $\mathrm{O}$ autor assim expõe: 
Esse tipo de conflito não é próprio de um Brasil moderno, mas de um Brasil arcaico. O buraco, porém, é um pouco mais embaixo: esse é o conflito do Brasil arcaico contra o Brasil moderno. E também o conflito que mostra de modo sangrento ações, no interior do próprio Estado, no sentido de amarrar e frear os propósitos modernizadores do governo: o que está em jogo é a viabilidade e a continuidade de sua política e, no limite, a sua própria continuidade (MARTINS, 1991, p. 55).

A perpetuidade do arcaico, nesse sentido, e, também, a partir desse argumento, induz a pensar que se trata de uma situação temporária a ser suprimida pela modernização. Para o autor, a permanência de relações arcaicas é, na verdade, reflexo do que as elites do país têm demonstrado: uma perspectiva retrógrada em que sua mentalidade reproduz a forma de exploração escrava do país no período colonial e imperial. Mesmo após a "Lei áurea", quando supostamente haveria uma liberação de mercado consumidor e de trabalhadores livres, "as elites deste país têm demonstrado [...] que os trabalhadores e os pobres são considerados residuais e descartáveis" (MARTINS, 1991, p. 59). Porém, não se trata de situações que são resultados das formas de pensamento retrógradas. A exploração do trabalho a partir do trabalho escravo na contemporaneidade não é fruto de anacronismos, mas sim, da modernização do modo de produção.

De certo, a expansão das fronteiras, como afirma Martins (1991), é um desdobramento da expansão territorial do capital e tem mobilizado mão de obra de outras regiões levando em consideração duas características. A primeira é a mobilização de mão de obra temporária, em que o trabalhador fica apenas alguns períodos do ano e retorna para seu local de origem. A segunda é a precarização das relações de trabalho visando à máxima exploração do trabalhador. Dessa maneira, a mão de obra é apenas um elemento da produção capitalista, podendo ser descartada de acordo com a demanda.

O agronegócio, por exemplo, não consegue manter a mão de obra de maneira efetiva nos locais de expansão e, por isso, precisa mobilizar em outras regiões. Ao mesmo tempo em que há uma necessidade de mão de obra temporária e precária, é preciso compreender que isso se dá com uma série de empecilhos, como, por exemplo, a não possibilidade de permanência dessa mão de obra por vários motivos, desde o custo de vida até o preço da terra etc. Outro empecilho é que as condições de vida que os migrantes muitas vezes enfrentam nas regiões de expansão se tornam fator de repulsão, num fluxo contrário ao que os atraiu. Um dos relatos de informantes da pesquisa indica isso. Em uma de suas viagens para trabalhar na colheita da batata em Minas Gerais, ele assim explica: 
Olha... batata é ruim, mas dá pra ganhar dinheiro, mas só que é uma história puxada, tem muitos caba lá que tão lá... trabalhei lá treze dias eu ganhei mil e trezentos reais, mas só Deus sabia quando é que eu, como eu sai de lá. Rapaz não dá pra mim não, aí eu voltei, toda vida eu aperreei (INFORMANTE E2, Morador de Esperantinópolis. Entrevista concedida em 14/09/2014)

A colheita da batata tem recrutado muitas pessoas na região do Médio-Mearim maranhense e muitos foram os relatos de sujeitos, nos trabalhos de campo, que migraram para atuarem na colheita de batata em busca de melhores condições de vida, mas que, diante da precariedade e da exaustiva jornada de trabalho, voltaram para seus municípios de origem. $\mathrm{O}$ interessante é que os próprios entrevistados ponderaram que esse tipo de trabalho na colheita de batata é "quase um trabalho escravo""

A fronteira tem sido o lócus das ocorrências de trabalho escravo no Brasil e o número de resgatados nessas regiões de expansão demonstra que o uso desse tipo de exploração da mão de obra é constante no modo de produção capitalista no país. Sobretudo nessas regiões, mas cada vez mais também em áreas urbanas, demonstrando que a preferência por formas de intensificação de exploração da mais valia em território brasileiro seguem o rumo da precarização do trabalho. Uma breve vista pela lista suja do trabalho escravo mostra isso. Empresas envolvidas nas mais diversas atividades aparecem, desde a criação de bovinos, construção civil, abertura de fazendas, cultivo de soja, milho, arroz, abacaxi, batata, dendê, café, cana-de-açúcar, produção de carvão vegetal, produção de álcool, setor têxtil etc. Setores da economia que são anunciados como sendo os carros chefes da elevação do PIB de exportação e, também, parte do discurso de modernização econômica do país. Essa constatação se junta ao fato de que, em 2013, pela primeira vez, o número de resgatados do trabalho escravo contemporâneo em zonas urbanas ultrapassou o número de libertados em zonas rurais. Dos 2.208 casos no país, 1.228 dos trabalhadores foram nas cidades, representando $56 \%$ do total.

Em 2013, ao todo, foram resgatadas 849 pessoas do trabalho escravo na construção civil, superando o número de trabalhadores resgatados no setor agrícola (342 casos) e pecuária (276 casos). Do total de trabalhadores resgatados, 173 pessoas foram retiradas de trabalho escravo somente no município de Conceição de Mato Dentro, em Minas Gerais ${ }^{8}$.

As atividades urbanas passaram a ter uma representatividade grande no número de resgatados do trabalho escravo. O cosmopolitismo que a cidade tem em relação à acumulação capitalista passa, também, ser sentido em relação à prática do aliciamento de trabalhadores para o trabalho escravo. 
No Maranhão, as adições de nomes na lista suja do trabalho escravo ainda seguem o padrão, sendo a maior parte de empresas e nomes individuais empenhados em atividades rurais, principalmente a pecuária bovina e a abertura de fazendas. Dos 33 nomes que estavam na lista suja do trabalho escravo, 32 se tratavam de fazendas e 1 se tratava especificamente de uma carvoaria (REPÓRTER BRASIL, 2015). Porém, esse número pode esconder uma série de situações individuais que não são denunciadas, ou mesmo, que as fiscalizações do Ministério do Trabalho não alcançam. O trabalho infantil doméstico e feminino pode ser incluído aqui, mostrando a naturalização da exploração de classes subalternas nas cidades. Além desses casos, o trabalho na construção civil é outro que tem o traço da exploração de classe. Segundo pesquisa do Departamento Intersindical de Estatística e Estudos Socioeconômicos (DIEESE) o número de trabalhadores da construção civil sem carteira assinada em 2012 chegou a mais de um milhão e meio, enquanto os trabalhadores com carteira chegam a aproximadamente 2,3 milhões. Ou seja, é mais que metade dos trabalhadores que atuam na construção civil. Os que indicaram não ter remuneração chegaram a mais de 75,3 mil trabalhadores. Os dados também mostram que 42,7\% dos trabalhadores trabalhavam mais de 49 h semanais no ano de 2000 e em 2012 esse número passou a ser de $27,8 \%$ dos trabalhadores. Apesar da queda, esse número ainda é grande. Os trabalhadores que recebiam até um salário-mínimo chegaram a mais de $17 \%$ do total. $\mathrm{O}$ trabalho na construção civil é uma atividade com baixa remuneração, com jornada intensa de trabalho pesado e com uma baixa escolaridade, tendo $50 \%$ dos trabalhadores sem instrução ou apenas com o ensino fundamental incompleto (DIEESE, 2012).

Aqui podemos retornar ao que José de Souza Martins fala e que foi citado mais acima. Apesar do empenho em querer analisar a contradição entre o que ele denominou de "Brasil moderno", com a permanência de situações que ele caracteriza como sendo arcaicas (num contexto pré-moderno), o autor peca ao querer imaginar que essas situações permanecem e se situam como processos que não se casam. O que José de Souza Martins considera como arcaico é, na verdade, não uma anomalia da modernidade, mas sim, resultado dela. A dicotomia existente entre o arcaico ou "não moderno", como descrito por Horácio Antunes de Sant'Ana Júnior (2004) e a modernidade do mundo atual pode ser entendida dentro da perspectiva da relação entre várias escalas e não a exterioridade do modo de produção. Para esse autor, que analisa o Acre e a Amazônia dentro da "brutal dialética entre local e global", ao contrário das interpretações feitas, na verdade, essa 
região é parte e resultado da relação entre essas duas escalas. Convencionou-se relacionar essa relação escalar dentro do âmbito do conflito, porém, desprezando que o global se faz no local e o local é parte do global como analisado por Anssi Paasi (2004) que faz uma análise das relações escalares dentro do conhecimento da realidade. A modernidade, dentro dessa relação de escalas, é tida como o global que se apresenta ao local num movimento hegemônico de subalternizar. O local aparece nas análises corriqueiras, apenas como o espaço da recepção da modernidade. Assim, a reflexão feita por Sant'Ana Júnior $(2004,2002)$ da empresa seringalista que é desenvolvida na Amazônia a coloca como parte do movimento da modernidade e não fora dela. É o local como parte do global e o global que se desenvolve não negando o local, mas se apropriando.

Zygmund Bauman (1998) considera, dentro dessa linha de análise entre linhas divisórias da modernidade, que entre "norma e normalidade" foi traçada uma separação arbitrária para designar o holocausto em relação à modernidade. Sendo assim, não é possível compreender na sua totalidade o holocausto somente a partir da especificidade histórica e cultural alemã, como uma anomalia. Para ele, o Holocausto deve sua existência a algumas instituições que são centrais na modernidade, como, por exemplo, o Estado, o aparato burocrático, a cultura da racionalidade, dentre outros. Mas, mais além, podemos ver o holocausto como parte da cultura de subarternização, que é integrante da cultura de racionalidade em que há a naturalização da exploração, da escravidão, da pobreza e precarização da vida. Assim, não é de surpreender que ele pode ser pensado como parte não anômala da modernidade e não uma exceção.

Essa maneira de se pensar acontecimentos ou espaços, que cotidianamente são interpretados como um desvio de conduta ou como formas anômalas da modernidade, pode ser trazida na análise do trabalho escravo contemporâneo para o modo de produção capitalista. Ele não é anômalo, passa a não ser exceção na reprodução capitalista, mas sim, fazer parte da regra no processo de produção, reprodução do capital e acumulação capitalista.

\section{O Maranhão como espaço do trabalho escravo: do legado do desenvolvimento à subalternidade espacial}

O Estado do Maranhão, na contramão do discurso dos grandes empreendimentos que se apresentam como redentores e portadores do desenvolvimento, apresentou em 2010 alguns dos piores índices sociais e econômicos do país. Segundo dados do Programa das Nações Unidas para o Desenvolvimento (PNUD), nesse ano, o Maranhão teve o 
segundo pior Índice de Desenvolvimento Humano (IDH) do país, com 0,639 de índice numa escala de 0 a 1, em que quanto mais próximo de 1 melhor é a situação do estado (PNUD, 2013). O IDH é o cruzamento de três elementos. O Maranhão ter apresentado o segundo pior Índice de Desenvolvimento Humano Municipal (IDHM) do país quer dizer que ao cruzar os dados da renda, saúde e educação obtém-se o valor 0,639. Pode-se analisar os três elementos que compõem o IDHM do estado do Maranhão e, dessa maneira, teremos a dimensão da longevidade como a que mais contribui para o IDHM do estado, sendo esta de 0,757 no ano de 2010, seguida pela renda, com índice 0,612 no mesmo ano, posteriormente vem a educação com índice de 0,562 (PNUD, 2013).

Apesar de o IDHM ter tido um crescimento 34,24\% entre 2000 e 2010, analisando-se outros indicadores sociais, como a mortandade de crianças com menos de um ano de idade, segundo a compilação feita pelo PNUD, no ano de 2010 foi de 28 para cada grupo de mil nascidos vivos. Comparando-se com o dado referente a média brasileira, a taxa foi de 16,7 mortos para cada grupo de mil nascidos vivos. Para se ter uma ideia da distância da situação do estado em relação à média do país, a meta definida pelas Nações Unidas para o Brasil era de 17,9 óbitos no ano de 2015, ou seja, em 2010 o Maranhão estava com mais de 10 mortes acima dessa meta. Outro indicador social que mostra o distanciamento do estado para a média do país é o de escolaridade da população adulta. O percentual da população adulta escolarizada no estado em 2010 foi de 44,36\%, enquanto que no país esse percentual nesse mesmo ano era de 54,92\%.

Esses dois indicadores mostram que ao estado tem sido legado um desenvolvimento aquém do que é disseminado com a instalação desses grandes empreendimentos, na verdade, um des-envolvimento. Os agentes dos grandes empreendimentos estão relacionados com a rede multimodal de transportes que associa transporte rodoviário, ferroviário e o complexo portuário do Itaqui, na capital do estado, São Luís. Esse complexo sistema de transporte de cargas serve ao escoamento da produção de soja que se expande, sobretudo no sul e leste do estado, à produção de eucalipto, que se espraia por várias regiões e à produção mineral e siderúrgica, com o escoamento da produção de minério de ferro da Serra de Carajás, no Pará, para São Luís, Maranhão, pela Estrada de Ferro Carajás (EFC). Elena Steinhorst Damasceno e Horácio Antunes de Sant'Ana Júnior (2013) escrevem sobre a "vocação industrial" para um dos espaços de instalação desses grandes empreendimentos, a Zona Rural II do município de São Luís: 
A existência de portos, estradas de rodagem e ferrovia e dos projetos e ações com vistas à ampliação dessa rede infraestrutural tem sido acionada por planejadores governamentais e organizações empresariais como um dos principais argumentos para produzir a imagem de uma "vocação industrial" para a Zona Rural II do município de São Luís. Essa imagem é associada à perspectiva de sua importância para impulsionar o "desenvolvimento" do Maranhão, o que a destinaria, então, a passar por fortes mudanças nas suas formas de apropriação e uso. Assim, desde a década de 1970, sucessivos governos estaduais e municipais buscam criar instrumentos legais que alterem seu status de zona rural, convertendo-a em zona indústria.

Essa vocação é utilizada como argumento para a instalação de infraestruturas logísticas na cidade de São Luís, gerando conflitos, situações de resistência e deslocamentos forçados dessas populações. Bartolomeu Rodrigues Mendonça (2013) faz uma análise de dois grandes empreendimentos (Usina Termoelétrica Itaqui e a Refinaria Premium I da Petrobrás $^{9}$ ) instalados na ilha de São Luís - MA e no município de Bacabeira-MA para compreender os deslocamentos de populações tradicionais. Nesse cenário, "nos processos de deslocamentos compulsórios, diversas mudanças ocorrem nos modos de vida das famílias atingidas" (idem, p. 03). Assim, o processo de modernização da economia maranhense, a partir da retomada do desenvolvimento nos moldes dos grandes empreendimentos, como o mesmo autor afirma: "projetos de infraestrutura planejados nos governos ditatoriais estão sendo retomados, intensificados e novos projetos e programas são elaborados e implementados, envolvendo agências governamentais e privadas" e que conta com "os deslocamentos compulsórios de grupos sociais considerados entraves ao modelo de desenvolvimento adotado pelo Estado e corporações privadas” (idem, p. 03).

Como resultado da história de implantação de projetos de desenvolvimento no Estado, os dados sobre trabalho escravo aparecem como uma contradição da dita modernização brasileira. Em 2013, o estado ocupava a $5^{\mathrm{a}}$ posição em número de resgates em seu território, como mostram os dados da CPT, e era o estado com maior número trabalhadores resgatados em outras regiões do país nesse mesmo ano. Durante o período de 2003 a 2013, foram resgatadas 6.174 pessoas de regime de trabalho escravo em todo o Brasil e que indicavam o Maranhão como sua residência de origem (CPT - Síntese Estatística, 2014).

A espacialização da exploração do trabalho mostra que o Maranhão ficou com desumanização do trabalhador. A seguir, mapa espacializando a distribuição do número de trabalhadores resgatados no Brasil segundo a residência de origem, em que a gradação de cores evidencia os estados que mais enviaram para o trabalho escravo (Mapa 01): 
Mapa 1: Espacialização dos trabalhadores resgatados de trabalho escravo por estado de residência - 2012

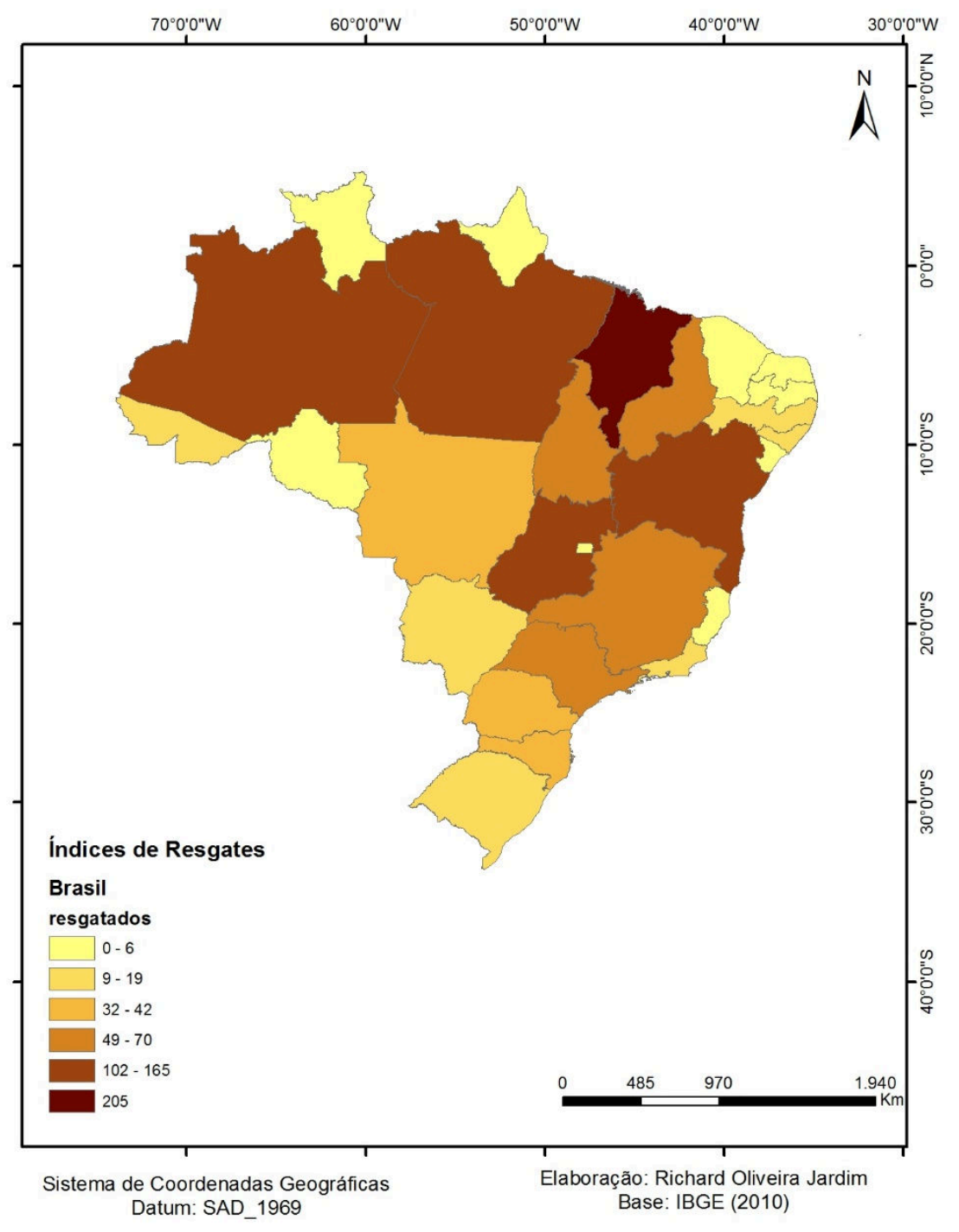

Fonte: CPT (2013); IBGE (2010); Elaboração: Richard Oliveira Jardim

No ano de 2012, com um total de 1.196 resgates no país, mais de $17 \%$ eram de residentes no estado do Maranhão (205 resgatados), garantindo ao estado o topo da lista de emissores de trabalhadores escravizados (CPT - Síntese Estatística, 2014). Essa situação nos lembra o que Josué de Castro (2007) escreve acerca do fim da escravidão formal. Ele lembra que, com a abolição da escravatura, os antigos escravos que já não viviam na senzala, tinham novos senhores e se amontoavam nas periferias, pelos casebres no campo, nas senzalas remanescentes da modernidade. Entendemos que a escravatura formal que acaba e com ela a invenção de uma crise de consciência no sistema, permanece numa nova relação entre a casa grande e a senzala, não mais com esses nomes, mas com 
essa mesma lógica. A casa grande está agora bem localizada, não mais na fazenda, com olhos atentos na senzala ao seu lado. Ela é moderna e usa de uma espécie de panóptico $^{10}$ para lidar com as novas formas de manutenção de seus escravos. A substituição do capitão do mato se dá de maneira cruel, já que põe em seu lugar a necessidade de sobrevivência do camponês e a miséria e a fome servem ao propósito de manter a liberdade do trabalhador controlado de maneira mais feroz que a chibata.

Uma visão ampliada dos lugares de origem desses trabalhadores no Maranhão mostra que as atividades modernas propaladas como sendo redentoras do estado, e que trariam o desenvolvimento deste, carregam junto com elas o trabalho escravo, tal como podemos observar no Mapa 02:

Mapa 02: Municípios de ocorrência de trabalho escravo, Maranhão - 2003 a 2012

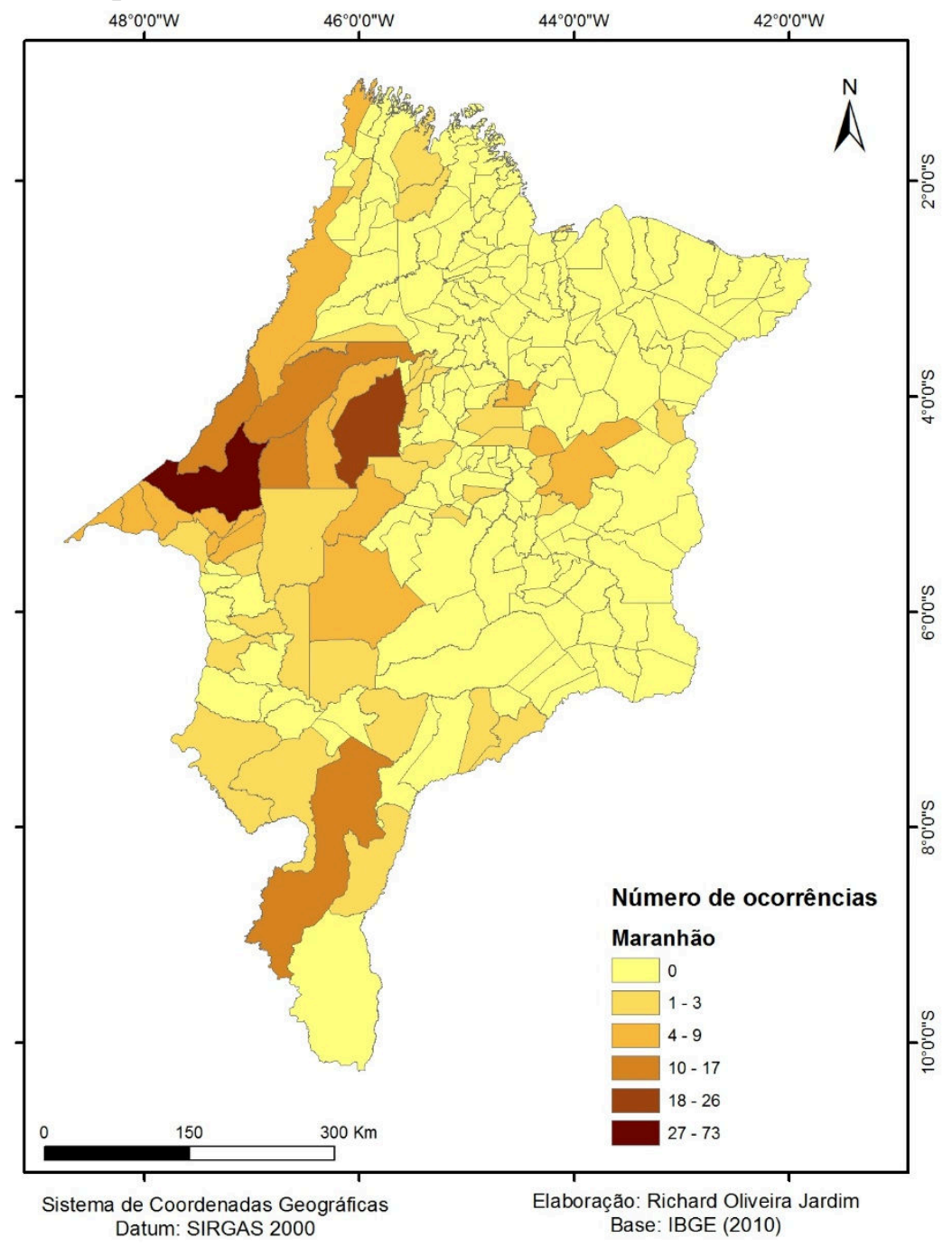

Fonte: CPT (2013); IBGE (2010); Elaboração: Richard Oliveira Jardim 
No estado do Maranhão, os municípios que mais tiveram casos no período de 2003 a 2013 foram: Açailândia (73 casos), Santa Luzia (26), Bom Jardim e Bom Jesus das Selvas (17 casos cada um), Itinga do Maranhão (12), Balsas (10). Todos esses municípios, com exceção de Balsas, se localizam na porção Oeste do estado e são tradicionalmente vinculadas à carvoaria/siderurgia, a pecuária bovina e a produção de madeira no estado.

De 2003 a 2012, a porção oeste do estado também centralizou a maior quantidade de ocorrências de trabalho escravo no estado. Nessa parte do Maranhão também houve o incentivo dado pela Lei Sarney de Terras ${ }^{11}$ que legalizou o latifúndio. Esse processo se deu contraditoriamente à colonização planejada que ocorreu com posseiros que já habitavam a região. Na verdade, a região também fez parte do movimento migratório de nordestinos que avançou pelo Maranhão em meados do século XX em direção à Amazônia brasileira em busca de terras livres e fugindo do latifúndio e secas do Nordeste ${ }^{12}$.

A construção da Estrada de Ferro Carajás (EFC) deu um novo sentido à ocupação da região, atraindo novos empreendimentos, como, por exemplo, a siderurgia que se instalou no município de Açailândia, principalmente. A dissertação de mestrado de Desni Lopes de Almeida (2012) aborda o que ela chama de "Os trilhos do desenvolvimento" no município de Açailândia, tratando com ênfase do caso do Povoado de Piquiá de Baixo para trazer as consequências da instalação dos grandes empreendimentos siderúrgicos na região. Então, a questão agrária, a pobreza, concentração de riquezas, o trabalho escravo, dentre outros, são citados pela autora para descrever o panorama da região.

Outra situação é apresentada com o município de Balsas, no sul maranhense. Ele se tornou referência na produção de soja, atividade com alto padrão técnico e investimentos em modernização. O grande número de expulsões de camponeses de suas terras nesse município ${ }^{13}$ ocasionado pela expansão das grandes fazendas expõe a população à pobreza e às condições de vida degradantes, em que a necessidade de se assalariar encontra como barreira seu nível de formação e acabam por serem aproveitados em postos de trabalho que exigem pouca formação, mas mais força física e resistência.

As ocorrências de trabalho escravo contemporâneo nas regiões que polarizam o agronegócio no estado, bem como os grandes projetos de desenvolvimento é o mote da reflexão em torno da qual o trabalho escravo é parte do mesmo processo de modernização da economia nacional. 
O mapa 03 mostra a distribuição dos resgatados por município de residência no Maranhão no período de 2003 a 2012.

Mapa 03: Espacialização dos trabalhadores resgatados de trabalho escravo por municípios maranhenses de residência, Maranhão - 2003 a 2012

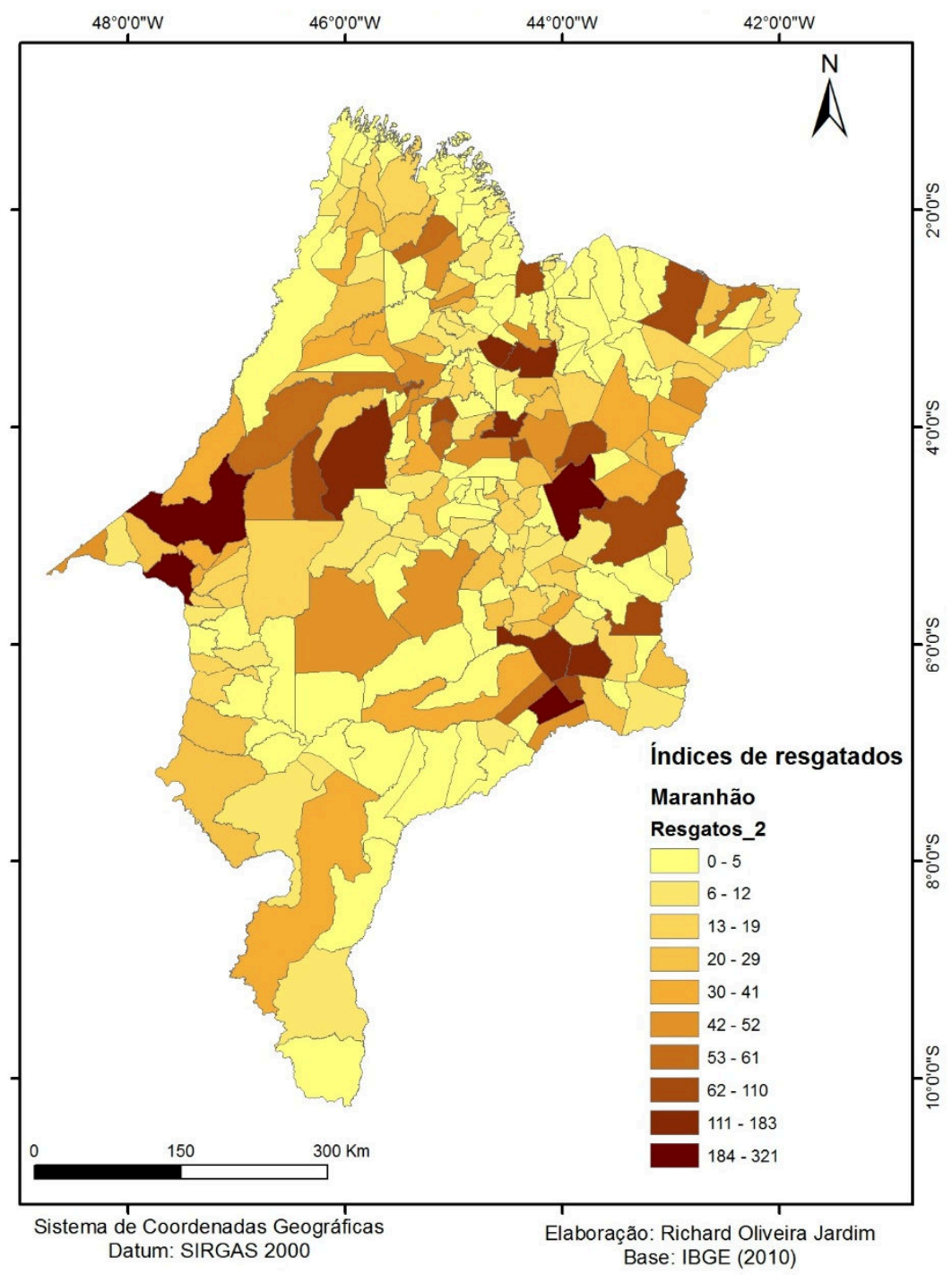

Fonte: CPT (2013); IBGE (2010); Elaboração: Richard Oliveira Jardim

Quase que 20\% do total de resgatados no Brasil no período de 2003 a 2012 eram de origem do Estado do Maranhão. A espacialização do trabalho escravo no Maranhão mostra que os municípios que mais enviaram trabalhadores aliciados para o trabalho escravo e que foram libertados entre os anos de 2003 a 2012 são: Codó (321 casos), Açailândia (295), Pastos Bons (265), Imperatriz (223). 
Aqui encontramos o espaço do estado do Maranhão como espaço subalterno para a produção capitalista no que diz respeito à mobilização de mão de obra para exploração da força de trabalho. A estrutura de subalternização passa por compreender a base estrutural de reprodução do capitalismo no Brasil e o papel do Estado nesse processo, bem como seus traços característicos. No estado, a propriedade da terra tem sido parte da reprodução e criação das elites locais, reproduzindo elementos do mando coronelista, mesmo de forma anacrônica. A ampliação da concentração fundiária tem ocasionado um amplo quadro de pobreza, sobretudo rural, que separa o trabalhador não só dos meios de produção, mas também da escolha da sua própria vida. A decisão de quem vive e dos que morrem ultrapassa o indivíduo, e recai em quem domina localmente o espaço dos sujeitos. Isso tem sido marcante em relação aos trabalhadores que migram do estado, não são suas escolhas que os fazem buscar novas formas de se viver, mas sim, condições que não são de seu controle.

A subalternidade a qual estamos nos referindo aqui, como espacializada e impressa no espaço a partir de espaços subalternizados, que mais do que simplesmente depósitos de populações e classes subalternas, a qual Antonio Gramsci (1999) se referiu, mas sim, espaços que se entrelaçam na história do capitalismo a partir da produção de capital e sua acumulação. Essa subalternidade que o Maranhão ganha, ou melhor, que é produzida de acordo com demandas do modo de produção só tem sentido com a leitura da transferência geográfica de valor que é encontrada como uma discussão importante na obra de Edward Soja (1993). Derivada da discussão geral de transferência de valor contida no livro de Karl Marx, "O Capital”, essa teoria reside na diferenciação de firmas, ramos, setores e localização. Como ele afirma:

Tudo o que é necessário para definir uma transferência geográfica de valor é dar ao capitalismo uma geografia concreta, deslocar a produção e a troca da cabeça a-espacial de um alfinete para uma espacialidade diferenciada e desigualmente desenvolvida (SOJA, 1993, p. 139).

A presença de áreas com maior ou menor produtividade, razões capital-trabalho altas e baixas, taxas variáveis de lucro, mas todas dentro do mesmo mercado integrado (SOJA, 1993) faz com que haja uma descompensação no ganho real de capital por região, aparecendo áreas mais densas do ponto de vista do capital e outras opacas. Porém, a característica de opaca não exclui a região da composição orgânica, estrutural e funcional do capitalismo. 
O autor concebe que só há transferência geográfica de valor, pois há um desenvolvimento geográfico desigual do capitalismo. Assim, a espacialidade desse processo "[...] é muito semelhante à da estrutura centro-periferia e aos mosaicos empíricos multiestratificados do desenvolvimento geograficamente desigual, com os quais está firmemente entrelaçado" (Idem). Basta revisitar os mapas apresentados aqui para ver que o Maranhão faz parte desse mosaico como a periferia do desenvolvimento capitalista com uma função bem definida, sobretudo com a emissão de mão de obra barata e precária.

Porém, apesar de ter processos de transferência, tal como descrito por Soja, entendemos que o Maranhão participa desse processo de uma maneira mais complexa. $\mathrm{O}$ envio de mão de obra se insere na transferência a que aludimos aqui, mas a partir da produção de capital feita a partir da apropriação do trabalho de maranhenses em outras regiões do país. Ela se assemelha ao que Edward Soja (1993) exprime como sendo um primeiro nível de transferência, porém, não é a mesma coisa. Para ele, esse primeiro nível se caracteriza pelas diferenças geográficas dos sistemas de produção e dos processos de trabalho associados. $\mathrm{O}$ valor adicionado por determinada região e a renda da população é menor em relação a outras regiões. A diferença reside em que a produção de capital se dá fora da região de origem, mas com sua população.

Assim, a subalternidade, expressa por essa geografia desigual e a pela transferência geográfica de valor, tem relação com a mobilização de mão de obra para proceder a produção de capital em regiões diversas. O espaço, em sua dinâmica de produção desigual explicita a produção capitalista de valor, com mobilização de mão de obra. A produção de valor, espacialmente localizada, tendo a produção de espaços subalternos é essencial.

\section{CONSIDERAÇÕES FINAIS}

A situação de pobreza do Maranhão faz com que a naturalização da superexploração e do trabalho escravo seja parte da própria dinâmica de produção do modo de produção capitalista. Assim, situações precárias de trabalho, condições subhumanas, muitas vezes são encaradas como parte do cotidiano do trabalhador maranhense.

Apesar de a reprodução capitalista não ser apenas baseada no trabalho escravo, atualmente, ela necessita desta forma de exploração do trabalho, criando uma situação em 
que se monta uma cadeia produtiva de relações que se tornam indispensáveis ao ciclo do capital. O Maranhão se tornou um espaço de envio de mão de obra, um bolsão de trabalhadores para abastecer a necessidade de crescimento do capitalismo no país, uma nova senzala que abastece a grande empresa capitalista com os novos escravos do desenvolvimento capitalista, pobres e miseráveis. $\mathrm{Na}$ verdade, o estado tem desempenhado um papel importante na exportação de mão de obra barata para todo o país, cumprindo o papel de um reservatório de trabalhadores de baixo custo, que serve à necessidade do capital se expandir com pouco investimento em força de trabalho.

O Maranhão se apresenta, nesse contexto, como um espaço de reserva de mão de obra, sobretudo, precária e vulnerável ao aliciamento para o trabalho escravo contemporâneo. Além dos casos registrados no estado, o que já mostra o papel da escravidão contemporânea no Maranhão, também os casos de trabalhadores maranhenses resgatados em outros estados. Esses casos mostram que o estado tem tido um papel importante para a reprodução do capital a partir da acumulação primitiva. Isso coloca em debate o uso desse tipo de exploração do trabalho no atual momento de desenvolvimento do capitalismo brasileiro. O capital se transforma em muitos aspectos, mas a maneira de exploração do trabalho em sua essência não muda. E a assimilação de formas não capitalistas não é uma novidade, mas sim uma constância. A utilização de trabalho escravo tanto em áreas de fronteira moderna como também em regiões de fronteira antiga denota a diversidade de situações no caso brasileiro.

\section{Notas}

\footnotetext{
${ }^{1}$ Portal Repórter Brasil: "MPF denuncia produtor de café de Caratinga/MG por trabalho escravo", acesso em: 14/10/2014. Disponível em: http://reporterbrasil.org.br/2014/08/mpf-denuncia-produtor-de-cafe-decaratingamg-por-trabalho-escravo/

2 Portal "A nova democracia": "Latifúndio semifeudal explora trabalho escravo no Maranhão". Acesso em 14/10/2014; Disponível em: http://www.anovademocracia.com.br/no-52/2164-latifundio-semifeudalexplora-trabalho-escravo-no-maranhao

${ }^{3}$ Portal "Tempos Novos": "MPF/MA denuncia fazendeiros por submeter pessoas a trabalho semelhante a escravo". Acesso em 14/10/2014; Disponível em: http://www.temposnovos.com.br/2013/05/20/mpfmadenuncia-fazendeiros-por-submeter-pessoas-a-trabalho-semelhante-a-escravo/

${ }^{4}$ Portal "Repórter Brasil": "Ministério Público denuncia juiz pela prática de trabalho escravo. Acesso em: 14/10/2014; Disponível em: http://reporterbrasil.org.br/2008/03/ministerio-publico-denuncia-juiz-pelapratica-de-trabalho-escravo/

5Portal "Repórter Brasil": "Tribunal rejeita denúncia e absolve juiz acusado de escravidão" Acesso em: 14/10/2014. Disponível em: http://reporterbrasil.org.br/2009/12/tribunal-rejeita-denuncia-e-absolve-juizacusado-de-escravidao/

6 Portal "Folha de São Paulo": "Irmão de Senadora é acusado explorar trabalho escravo". Acesso em: 14/10/2014; Disponível em: http://www1.folha.uol.com.br/poder/2013/11/1369577-irmao-de-senadora-eacusado-de-explorar-trabalho-escravo.shtml
} 
${ }^{7}$ Em entrevista coletiva feita no município de Esperantinópolis, os entrevistados, ao escutarem a fala do senhor de 42 anos, começaram a comentar que se tratava de trabalho escravo, pelas dificuldades que ele enfrentou na colheita da batata em Minas Gerais.

${ }^{8}$ Portal "Construção Mercado": "Construção civil é o setor com mais casos de trabalho escravo, mostra balanço do MTE". Acesso em: 16/10/2014; Disponível em: http:/construcaomercado.pini.com.br/negocios-incorporacao-construcao/construcao/construcao-civil-e-osetor-com-mais-casos-de-trabalho-312679-1.aspx

${ }^{9}$ A Refinaria Premium I teve sua obra cancelada no início do ano de 2015, após já ter sido feita a terraplanagem do terreno de sua instalação, no município de Bacabeira-MA, vizinho a São Luís-MA.

${ }^{10}$ Refere-se a um mecanismo de controle social que é citado por Foucault $(2001 ; 2002)$. Ele afirma que para “[...] ser eficiente, o panóptico deve ser 'visível' e 'inverificável'; o indivíduo não precisa saber que está sendo observado, mas precisa ter certeza que poderá sê-lo a qualquer momento" (2001, p. 166).

${ }^{11}$ Lei $n^{0} 2.979 / 1969$, criada no Maranhão no governo estadual de José Sarney. A lei consolidava um projeto modernizador da agricultura no Estado, vendendo terras para empresários e com financiamentos da SUDENE e Banco do Nordeste.

12 Importante contribuição para entender esse movimento é dado por Manuel Correia de Andrade (1968) que distingue as várias frentes que adentraram o território maranhense pelo Piauí, na divisa do Maranhão com Teresina-PI e com Floriano-PI e descreve seu deslocamento pelo estado.

13 Os trabalhos de Maristela de Paula Andrade (2008), Maria da Glória Rocha Ferreira (2008) é possível uma análise do plantio da soja e suas consequências para os camponeses na região sul do Maranhão é abordado.

\section{REFERÊNCIAS}

ALMEIDA, Desni Lopes. Os trilhos do desenvolvimento na Amazônia Maranhense conflitos e contrates: o caso Piquiá de Baixo Açailândia - MA. Dissertação (Mestrado em Desenvolvimento Sócio Espacial e Regional), Universidade Estadual do Maranhão, São Luís-MA, 2012.

ANDRADE, Manuel Correia de. Paisagens e Problemas do Brasil (aspectos da vida rural brasileira frente à industrialização e ao crescimento econômico). São Paulo: Editora Brasiliense, 1968.

ANDRADE, Maristela de Paula; SOUZA FILHO, Benedito (Org.). Os gaúchos descobrem o Brasil: projetos agropecuários contra a agricultura camponesa. São Luis: Edufma, 2008.

BAUMAN, Zygmunt. Modernidade e Holocausto. Rio de Janeiro: Jorge Zahar Ed, 1998.

BRASIL. Código penal. Decreto-Lei n_2.848, de 7 de dezembro de 1940. Disponível em: http://www.planalto.gov.br/ccivil_03/decreto-lei/del2848.htm; Acesso em $19 / 12 / 2014$

CASTRO, Josué de. A reivindicação dos mortos. In: FERNANDES, Bernardo Mançano; GONÇALVES, Carlos Walter Porto. Josué de Castro, vida e obra. Ed. $2^{\circ}$. São Paulo: Expressão Popular, 2007.

COMISSÃO PASTORAL DA TERRA. SÍNTESE ESTATÍSTICA (provisória 1, em 30/12/2013) - CAMPANHA DA CPT CONTRA O TRABALHO ESCRAVO, 2013. (Arquivo digital) 
DIEESE. Perfil dos trabalhadores na construção civil no estado da bahia. DIEESE, Brasília-DF, 2012

ESTERCI. Neide. Escravos da desigualdade: Um estudo dobre o uso repressivo da força de trabalho hoje. Rio de Janeiro: Centro Edelstein de Pesquisas Sociais, 2008.

FERREIRA, Maria da Glória Rocha. A dinâmica da expansão da soja e as novas formas de organização do espaço na região de Balsas - MA. Rio de Janeiro: Universidade Federal do Rio de Janeiro, Instituto de Geociências, 2008. (Doutorado em Geografia)

FOUCAULT, Michel. A Verdade e as Formas Jurídicas (trad. Roberto Cabral de Melo Machado e Eduardo Jardim Morais). Rio de Janeiro: Nau, 2001.

FOUCAULT, Michel. Vigiar e Punir (trad. Raquel Ramalhete). 28ª ed. Petrópolis: Vozes, 2002.

GRAMSCI, Antonio. Cadernos do Cárcere: Introdução ao estudo da filosofia. A filosofia de Benedetto Croce. Rio de Janeiro: Ed. Civilização Brasileira, 1999.

MARTINS, José de Souza. Expropriação e Violência. A questão política no campo. 3. Ed. São Paulo: HUCITEC, 1991.

MENDONÇA, Bartolomeu Rodrigues. PEREGRINOS DO DESENVOLVIMENTO: conflitos socioambientais, deslocamentos compulsórios e resistências nos casos de instalação de projetos industriais em São Luís e Bacabeira - MA. In Anais do XXIX Congresso Latinoamericano de Sociologia - ALAS. Chile: ALAS, 2013.

MOURA, Flávia de Almeida. Escravos da precisão: economia família e estratégias de sobrevivência de trabalhadores rurais em Codó (MA). São Luis: EUFMA, 2009.

PAASI, Anssi. Place and region: looking through: the prism of scale. Progress in Human Geography. N. 28. V. 4, 2004. p. 536-546.

PNUD. Índice de Desenvolvimento Humano Municipal Brasileiro. - Brasília: PNUD, Ipea, FJP, 2013

REPÓRTER BRASIL. Lista Suja do Trabalho escravo 2014. Disponível em: http://reporterbrasil.org.br/listasuja/resultado.php; acesso em 21/01/2015.

SANT'ANA JÚNIOR, Horácio Antunes. Florestania: a saga acreana e o Governo da Floresta. Rio de Janeiro: PPGSA/IFCS/UFRJ, 2002. (Tese de Doutorado).

SANT'ANA JÚNIOR, Horácio Antunes. Socioambientalismo e desenvolvimento na Amazônia: o caso do Acre. Revista de Políticas Públicas. São Luis - MA, v. 8, n.1, p. 61-81, 2004. 
SOJA, Edward W. Geografias pós-modernas: a reafirmação do espaço na teoria social. (Tradução: Vera Ribeiro). Rio de Janeiro: Jorge Zahar ed, 1993.

DAMASCENO, Elena Steinhorst; SANT'ANA JÚNIOR, Horácio Antunes de. Neodesenvolvimentismo e conflitos relacionados ao território na resex de tauá-mirim, são luís - MA. In: $37^{\circ}$ Encontro Anual da ANPOCS. Anais do $37^{\circ}$ Encontro Anual da Anpocs, de 23 a 27 de setembro de 2013, em Águas de Lindóia/SP, 2013.

Recebido em 17/10/2016

Aceito para publicação em 18/05/2018. 